\title{
Conservation of ParaHox genes' function in patterning of the digestive tract of the marine gastropod Gibbula varia
}

\author{
Leyli Samadi* and Gerhard Steiner
}

\begin{abstract}
Background: Presence of all three ParaHox genes has been described in deuterostomes and lophotrochozoans, but to date one of these three genes, Xlox has not been reported from any ecdysozoan taxa and both Xlox and Gsx are absent in nematodes. There is evidence that the ParaHox genes were ancestrally a single chromosomal cluster. Colinear expression of the ParaHox genes in anterior, middle, and posterior tissues of several species studied so far suggest that these genes may be responsible for axial patterning of the digestive tract. So far, there are no data on expression of these genes in molluscs.

Results: We isolated the complete coding sequences of the three Gibbula varia ParaHox genes, and then tested their expression in larval and postlarval development. In Gibbula varia, the ParaHox genes participate in patterning of the digestive tract and are expressed in some cells of the neuroectoderm. The expression of these genes coincides with the gradual formation of the gut in the larva. Gva-Gsx patterns potential neural precursors of cerebral ganglia as well as of the apical sensory organ. During larval development this gene is involved in the formation of the mouth and during postlarval development it is expressed in the precursor cells involved in secretion of the radula, the odontoblasts. GvaXolx and Gva-Cdx are involved in gut patterning in the middle and posterior parts of digestive tract, respectively. Both genes are expressed in some ventral neuroectodermal cells; however the expression of Gva-Cdx fades in later larval stages while the expression of Gva-Xolx in these cells persists.
\end{abstract}

Conclusions: In Gibbula varia the ParaHox genes are expressed during anterior-posterior patterning of the digestive system. This colinearity is not easy to spot during early larval stages because the differentiated endothelial cells within the yolk permanently migrate to their destinations in the gut. After torsion, Gsx patterns the mouth and foregut, Xlox the midgut gland or digestive gland, and $C d x$ the hindgut. ParaHox genes of Gibbula are also expressed during specification of cerebral and ventral neuroectodermal cells. Our results provide additional support for the ancestral complexity of Gsx expression and its ancestral role in mouth patterning in protostomes, which was secondarily lost or simplified in some species.

\section{Background}

The three ParaHox genes, Gsx, Xlox, and Cdx, were first described as a gene cluster in the invertebrate chordate Branchiostoma floridae (amphioxus) by the elegant work of Brooke et al. 1998 [1]. ParaHox and Hox genes are believed to have evolved from a single ancient proto-Hox cluster composed of two to four genes prior to the divergence of cnidarians and bilaterians. Thus, they are con-

* Correspondence: leili.samadi@univie.ac.at

${ }^{1}$ Molecular Phylogenetics, Department of Evolutionary Biology, Faculty of Life Sciences, University of Vienna, Vienna, Austria

Full list of author information is available at the end of the article sidered evolutionary sister (or paralogue) clusters [1-7]. Vectorial expression of the ParaHox genes in anterior, middle, and posterior tissues of amphioxus and its distinct similarities to vertebrate ParaHox gene expression suggest that these genes may be responsible for axial patterning of the digestive tract $[1,3]$.

\section{Expression of ParaHox genes in deuterostomes}

ParaHox gene expression and genomic organisation have been studied extensively in deuterostomes. In Vertebrates, Gsh1 and Gsh2 genes are restricted to the central nervous system (CNS) [8-13]. Vertebrate Xlox is 
expressed both in CNS and the developing gut [14-20]. $C d x 1$ to $C d x 4$ genes of vertebrates are involved in posterior patterning, since they are expressed in posterior parts of CNS and gut [21-24]. Within invertebrate deuterostomes, apart from amphioxus, expression of ParaHox genes has been traced in the ascidian, Ciona intestinalis, the echinoderm, Strongylocentrotus purpuratus, and in a starfish, Archaster typicus [25-29]. In invertebrate deuterostomes, Gsx is expressed more anteriorly and only in the nervous system, while $X l o x$ and $C d x$ are expressed within the gut primordium with Xlox anterior to $C d x$ [25-28]. In the sea star, however, the Aty-Xlox expression is found in the archenteron as well as in ectodermal cells near the vegetal region of early and mid-gastrula stages [29]. This expression pattern is very different from those of Xlox homologues in other deuterostomes.

\section{Expression of ParaHox genes in ecdysozoans}

In ecdysozoans, Gsx expression has been documented in the insects Drosophila and Tribolium [30,31]. Insect Gsx (called ind) is expressed along a pair of medio-lateral neural columns and promotes neural precursor formation in the medial and intermediate columns of the CNS [30,31]. The central ParaHox gene, Xlox, is lost in all insect genomes sequenced to date. Caudal has been known as a posterior patterning gene in several arthropods during segmentation [32-42]. $C d x$ is also a posterior patterning gene in the nematode Caenorhabditis elegans. Here, this gene is called pal-1 and patterns the precursor cells of alae and rays in the posterior of the worm [43]. Gsx and Xlox orthologs are absent in the nematode [44].

\section{Expression of ParaHox genes in lophotrochozoans}

Within Lophotrochozoa, expression of the full complement of ParaHox genes has been described in the polychaetes Capitella teleta, Nereis virens, and Platynereis dumerilii [45-48]. In Capitella, Gsx is not expressed in the gut but in some neuroectoderm cells of the anterior brain [45]. This is very different from the expression of Gs $x$ in the nereid polychaetes, Nereis virens and Platynereis dumerilii [46,48]. Nereid Gs $x$ is first expressed in symmetrical bilateral domains in the dorso-medial episphere of the trochophore $[46,48]$. Later this gene is expressed during formation of the midgut and the posterior foregut in both nereids [46,48]. Xlox is expressed throughout the midgut in the polychaete Capitella [45]. This is also true for the Xlox genes, named Lox3 in the leeches Helobdella triserialis and Hirudo medicinalis $[49,50]$. Expression of Xlox is not reported in the nervous system of these annelids $[45,49,50]$. Nereid Xlox is also expressed in the midgut, but in contrast to Capitella and the leeches its expression is additionally detected in the CNS $[46,48]$. As in arthropods, $C d x$ is a posterior patterning gene in the annelids. However in Platynereis,
Nereis, Tubifex, and Capitella there are both anterior and posterior expression domains of $C d x$ [45-48,51]. Capitella $C d x$ is expressed in the cerebral ganglia, $N v i-C d x$ expression is detectable in the ventral nervous system, while $P d u-C d x$ is not detected in the nervous system [4548]. Expression of $C d x$ is also detected in more posterior parts of the gut [45-48]. Moreover, $C d x$ is expressed in the posterior ectodermal cells that form the pygidium epidermis of both nereids [46-48]. Additionally, $C d x$ expression can be traced in mesodermal cells in Capitella, Tubifex, and Platynereis [45,47,48,51].

Little is known of ParaHox genes in other Lophotrochozoa than annelids [52-55]. The only available data are on the $C d x$ gene expression during the early development of the marine limpet, Patella vulgata [53]. Pvu-Cdx is expressed at the onset of gastrulation in the ectodermal cells at the posterior edge of the blastopore and in the paired mesentoblasts [53]. During trochophore larval stage, $P v u C d x$ is expressed in the posterior neurectoderm of the larva, as well as in part of the mesoderm [53]. Within Mollusca, a full complement of ParaHox genes has been shown for the chiton Nuttallochiton mirandus and the scallop Pecten maximus [54,55]. However the information is limited to partial homeobox sequences, whereas expression patterns of Gs $x$ and Xlox or chromosomal organisation of ParaHox genes have not been reported yet in any mollusc species.

\section{Ancestral role of ParaHox genes}

Holland (2001) elaborated the hypothesis of the ancestral role of ParaHox genes proposed by the original work of Brooke et al. 1998 [1,3]. Holland's hypothesis proposes that the three ParaHox genes originated from the Proto Hox gene cluster and pattern anterior, middle and posterior gut regions in a colinear manner in basal animals [3]. According to this hypothesis, a link of Gsx and anterior gut development existed in basal animals. However, Gsx is not expressed in the anterior gut of deuterostomes. This is explained by the loss of the primary mouth and formation of a secondary mouth in deuterostomes [3].

\section{Aim}

Gastropoda is undoubtedly the most successful taxon of the Mollusca, embracing more than $80 \%$ of all mollusc species [56]. The vetigastropod Gibbula varia L. is a shallow subtidal top shell snail with encapsulated development. The lecithotrophic larval development is completed within the eggs. The juveniles leave the gelatinous egg masses only after metamorphosis. In order to elucidate the function of the ParaHox genes in molluscs and to gain broader insights into the evolution of the ParaHox genes in the Lophotrochozoa, we describe the sequences as well as expression patterns for all three ParaHox orthologues by whole mount in situ hybridiza- 
tion from embryonic through juvenile stages in the top shell Gibbula varia. This is the first report of expression patterns of the full ParaHox complement in a mollusc.

\section{Results Gibbula varia life history}

Gibbula varia is a dioecious species. The eggs fertilized via copulation are laid in gelatinous egg masses (additional file 1, Figure S1A, S1B, S1C). Development of the embryos and larvae takes place inside the egg capsule and takes about four days. The main stages of G. varia development are presented in Table 1. Epibolic gastrulation occurs by the micromeres rapidly spreading downwards and enclosing the macromeres. The blastopore, being wide at first, gradually becomes constricted at 10 to 12 hours post fertilization (hpf), when the trochoblasts start to become ciliated. At $16 \mathrm{hpf}$, the prototroch is clearly visible as a circular ciliary band, separating the trochophore larva's episphere from the hyposphere (additional file 1, Figure S1D). There is no sign of apical cilia (apical tuft) at any stage in the development of the trochophore, although the pretrochal cells were observed to be smaller than those of the posttrochal region (additional file 1, Figure S1D). By this stage the blastopore gradually moves to a position just below the prototroch, forming the stomodeum. Simultaneously, the shell-gland invagination appears as a thin patch of cells gradually spreading over the dorsal region of the larva (additional file 1, Figure S1D). At $18 \mathrm{hpf}$, the late trochophore larva comprises a prototroch, the shell field surrounded by the mantle edge, and a pedal rudiment (additional file 1, Figure S1E). The late trochophore (24 hpf) turns into an encapsulated pretorsional veliger larva by differentiation of the prototroch to a distinct velum (additional file 1,
Figure S1F). The mantle fold and mantle cavity become visible mid-ventrally on the posterior surface of the pedal rudiment (additional file 1, Figure S1E, S1G). At $36 \mathrm{hpf}$, the pretorsional veliger has a velum, an apical organ marked by apical cilia (apical tuft), a mouth opening, and a pedal rudiment with the operculum anlage (additional file 1, Figure $\mathrm{S} 1 \mathrm{H}$ ). The first $90^{\circ}$ of torsion take place between $36-48 \mathrm{hpf}$, presumably by contraction of the larval retractor (shell) muscle. This results in a $90^{\circ}$ displacement of the mantle cavity to the right side, and, when viewed from the front, the foot and velum are rotated anti-clockwise in relation to the protoconch. The remaining part of torsion is completed within one day while the velum gradually becomes reduced in size and splits ventrally (additional file 1, Figure S1I). At $60 \mathrm{hpf}$, the operculum appears in the posttorsional veliger larva (additional file 1, Figure S1I). The radula and cephalic eyes appear about three days after fertilization. As the eyes form, the cephalic tentacles begin to appear as outgrowths of the prevelar surface. The juvenile hatches on the fourth day of development (about $96 \mathrm{hpf}$ ) and after that mineralization of the shell begins. The animals become sexually mature after 11-12 months.

\section{Development of gut in G. varia}

The development of the digestive tract starts with the development of the stomodeum (future mouth opening) in the trochophore (additional file 1, Figure S1E). The mouth opens during the pretorsional veliger stage (additional file 1, Figure S1H, S1J) whereas the anus opens in the late posttorsional stage at the site of a few ciliated cells (anal markers). The development of the digestive tract is very similar to that described in G. cineraria and Haliotis tuberculata $[57,58]$. The digestive gland begins

\section{Table 1: Timing of developmental stages of Gibbula varia (at $\left.22^{\circ} \mathrm{C}\right)$; different stages of larval development and metamorphosis of G. varia inside the gelatinous egg capsules before hatching.}

\begin{tabular}{|c|c|}
\hline $\begin{array}{l}\text { Name of stage and approximate time of } \\
\text { development (hpf) }\end{array}$ & Brief description of main features \\
\hline Early Trochophore Larva (12 hpf) & $\begin{array}{l}\text { The pretrochal cells are smaller than the posttrochal cells; prototroch starts to form by } \\
\text { cilliation of trochoblasts; shell gland starts to evaginate; foot rudiment and stomodaeum } \\
\text { are not completely formed. }\end{array}$ \\
\hline Late Trochophore Larva (18-24 hpf) & $\begin{array}{l}\text { The larva comprises a prototroch, shell field surrounded by mantle edge, a pedal } \\
\text { rudiment, and stomodaeum. }\end{array}$ \\
\hline Pretorsional veliger larva (36-48 hpf) & $\begin{array}{l}\text { The mantle and mantle cavity form. The larva has a velum, apical organ marked by apical } \\
\text { cilia, mouth opening, and pedal rudiment with anlage of operculum. }\end{array}$ \\
\hline Post-torsional veliger larva ( $60 \mathrm{hpf})$ & $\begin{array}{l}\text { The mantle lies over the back of the head and the velum gradually splits ventrally, the } \\
\text { operculum apears. }\end{array}$ \\
\hline Metamorphotic (competence) stage (72 hpf) & $\begin{array}{l}\text { Eye rudiments and cephalic tentacles begin to form in the prevelar area. The anlage of the } \\
\text { radula becomes visible. }\end{array}$ \\
\hline Encapsulated juvenile & Velum is completely lost; eyes and cerebral tentacles are formed. \\
\hline Hatchling (96 hpf) & The encapsulated juvenile hatches and shell mineralization begins. \\
\hline
\end{tabular}


to differentiate on the left side of the veliger just before torsion sets in $[57,58]$. The gut develops from differentiated endodermal cells initially scattered within the yolk in the pretorsional veliger. They later migrate to the yolk boundaries to form the definitive midgut in the posttorsional veliger $[57,58]$. Later, the hindgut develops from actively dividing cells of the digestive gland migrating to their final positions in the intestine [57,58]. The competent larva's digestive system comprises a mouth opening and a bipartite oesophagus (the anterior part immediately behind the buccal cavity is not effected by torsion, the mid oesophagus includes a portion affected by the torsion), a stomach with the digestive gland, the hindgut leading to the anus that opens into the mantle cavity over the back of the head (additional file 1, Figure S2A and S2B). The radula anlage is a ventral differentiation of the foregut where mesenchym cells aggregate. The radula teeth become visible in the competent larva at the distal end of the radula sheath (additional file 1, Figure S2A and S2B).

\section{ParaHox gene sequences}

The entire coding sequences for all three G. varia ParaHox genes were isolated by a combination of $3^{\prime}$ and $5^{\prime}$ rapid amplification of cDNA ends (RACE, see Methods). $3^{\prime}$ and 5' RACE together yielded a complete cDNA of 885 bp with the complete open reading frame (ORF) of 519 bp (172 amino acids) for Gva-Gsx, a complete cDNA of 1739 bp with complete ORF of $1002 \mathrm{bp}$ (333 amino acids) for Gva-Xlox, and a complete cDNA of 1466 bp with complete ORF of $976 \mathrm{bp}$ (325 amino acids) for Gva-Cdx. Alignments of each G. varia ParaHox amino acid sequence to orthologs of other species are shown in additional file 2, Figure S3, S4, and S5. Beside the homeobox which is the main region of conservation between ParaHox genes, further conserved domains are the $\mathrm{N}$-terminal domain in Gsx, and the hexapeptide motifs just upstream of the homeodomains in both $X l o x$ and $C d x$ (Additional file 2, Figure S3, S4, and S5). The classification of the G. varia ParaHox genes into their orthology groups is apparent from phylogenetic analyses (Figure 1). The species names and accession number of the genes used in phylogenetic analysis are provided in additional file 2 . Although the phylogenetic analysis clearly assigns the Gibbula paraHox genes to the Gsx, Xlox and Cdx classes with high support values, the internal grouping remains unclear.

\section{ParaHox gene expression in the trochophore larva}

We did not detect Gva-ParaHox transcripts by wholemount in situ hybridization (WMISH) in developmental stages before the trochophore stage. A scanning electron micrograph (SEM) of a late trochophore larva (18-24 hpf) is shown in Figure 2A.
The expression pattern of Gva-Gsx is rather dynamic. The first signs of transcripts of Gva-Gsx are already detected at $12 \mathrm{hpf}$ in early trochophore larvae, when a pair of intensive, bilateral expression domains appears in the dorso-medial episphere (Figure 2B). When viewed from the anterior, each pair of expression domains appears to be composed of 4-5 Gva-Gsx-positive cells, presumably in the area of future cerebral ganglia (Figure $2 \mathrm{C})$. This pattern of expression continues in $18 \mathrm{hpf}$ trochophores (Figure 2D and 2E). Here, the pattern of expression becomes considerably more complex. In addition to the paired expression domains in the dorsomedial episphere, Gva-Gsx transcripts can now be detected in a pair of cells at the tip of the developing apical sensory organ (Figure 2D and 2E). These two GvaGsx-positive cells at the tip of the apical organ do not bear any cilia or apical tuft in the trochophore stage of $G$. varia (Figure 2F). The expression of Gva-Gsx in the apical sensory organ is restricted to two groups consisting of three sensory cells (Figure 2G). Beside the expression in prospective neural or sensory tissues, Gva-Gsx transcripts are also detected around the stomodeum where they appear for the first time in trochophore $18 \mathrm{hpf}$ in two intensely stained bilateral semicircular clusters located anteriorly at the sides of the mouth and a less intensely stained semicircular domain at the posterior part of the mouth (Figure 2D and 2H). Figures $2 \mathrm{H}$ and 2I show the trochophore stomodaeum and Gva-Gsx expression around it at $18 \mathrm{hpf}$. About $24 \mathrm{hpf}$, Gva-Gsx is expressed in a complete circle around the stomodeum (Figure 2J) and in three episphere domains: a pair of adjacent cells at the tip of the apical sensory organ, and two pairs of cell groups dorsolaterally marking presumptive sites of future cephalic neuroectodermal differentiation (Figure 2K).

Gva-Xlox transcription begins later than Gva-Gsx expression. No expression is detectable until $24 \mathrm{hpf}$ when Gva-Xlox transcripts appear in a group of cells located ventrally in the hyposphere and in a pair of symmetrical expression domains in the medio-ventral episphere of the trochophore larva (Figure $2 \mathrm{~L}$ and $2 \mathrm{M}$ ). These symmetrical expression areas are located ventrally of the more intensely stained Gva-Gsx expression domains in the pretrochal area. Gva-Xlox is also expressed in the hyposphere in 8-9 cells forming a semicircle around the anal marker (Figures $2 \mathrm{~N}$ and $2 \mathrm{O}$ ). These weakly stained Gva$X l o x$-positive cells are probably part of ventral neuroectoderm.

Gva-Cdx transcripts are first detected in the early trochophore larva (12 hpf). It is expressed at 12 and $18 \mathrm{hpf}$ in two domains in the ventral vegetal plate: one in an area of presumptive posterior neuroectoderm, the other in a bilateral pair of cells in the interior of the larva (Figure 2P 


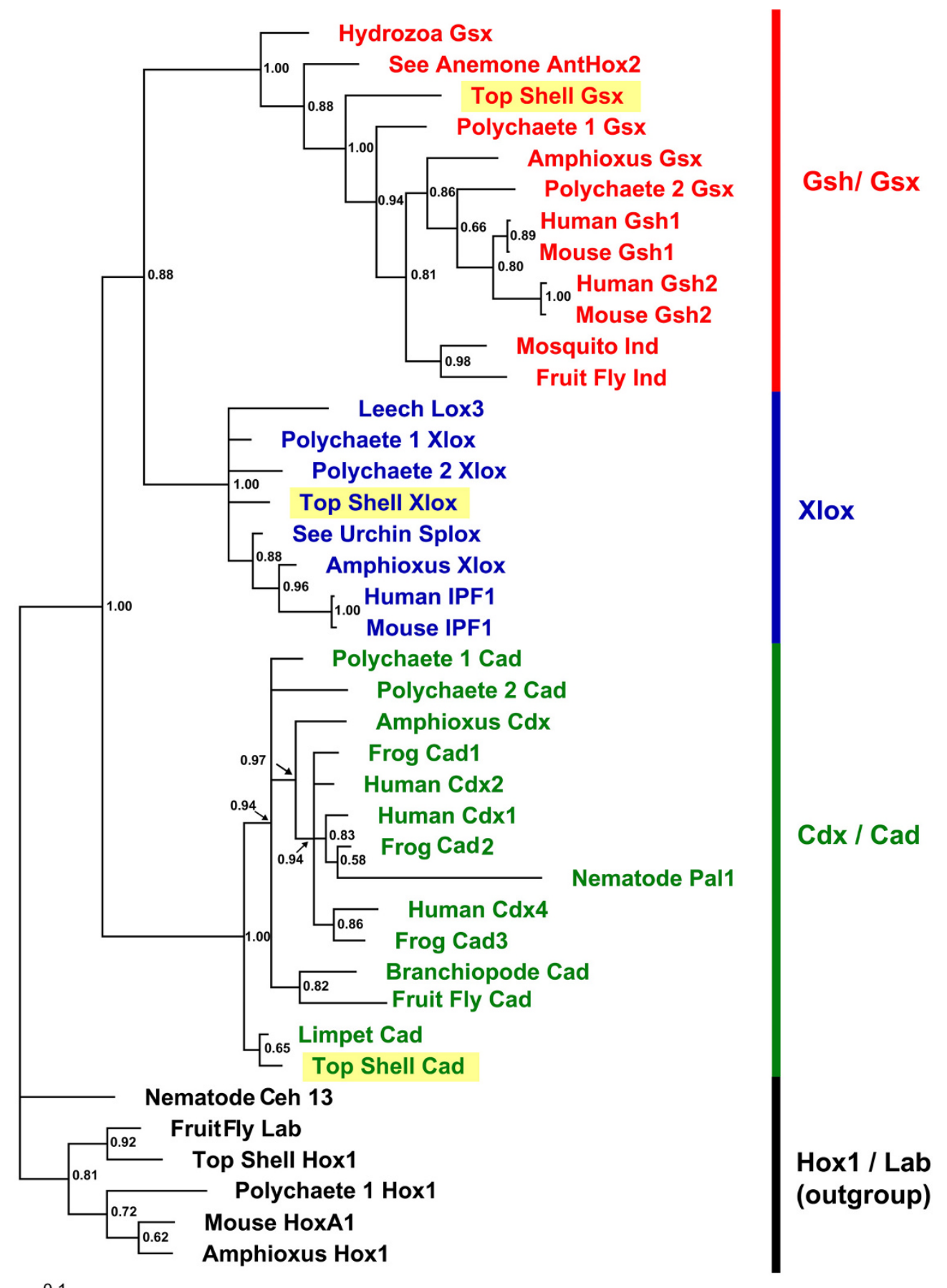

Figure 1 Phylogenetic reconstruction of ParaHox genes. The tree is from Bayesian likelihood analysis using MrBayes: half compatibility consensus from five million replicates, burn-in of 5,000 replicates. The tree is built with the amino-acid sequences of the homeodomain and the flanking region. Support values of branches are posterior probabilities of Bayesian likelihood. Hox1 sequences of several bilaterians are used as outgroup (black). Groupings of the ParaHox genes are strongly supported. Gsx/Gsh sequences are shown in red, Xlox sequences in blue, and Cad/Cdx in green. Yellow rectangles highlight ParaHox sequences of G. varia. Amphioxus: Branchiostoma floridae, Branchiopode: Artemia franciscana, Frog: Xenopus tropicalis, Fruit fly: Drosophila melanogaster, Human: Homo sapiens, Hydrozoa: Podocoryne carnea, Leech: Hirudo medicinalis, Limpet: Patella vulgata, Mouse: Mus musculus, Mosquito: Anopheles gambiae, Nematode: Caenorhabditis elegans, Polychaete 1: Platynereis dumerilii, Polychaete 2: Capitella teleta, Sea Anemone: Nematostella vectensis, Sea Urchin: Strongylocentrotus purpuratus, Top Shell: Gibbula varia. 


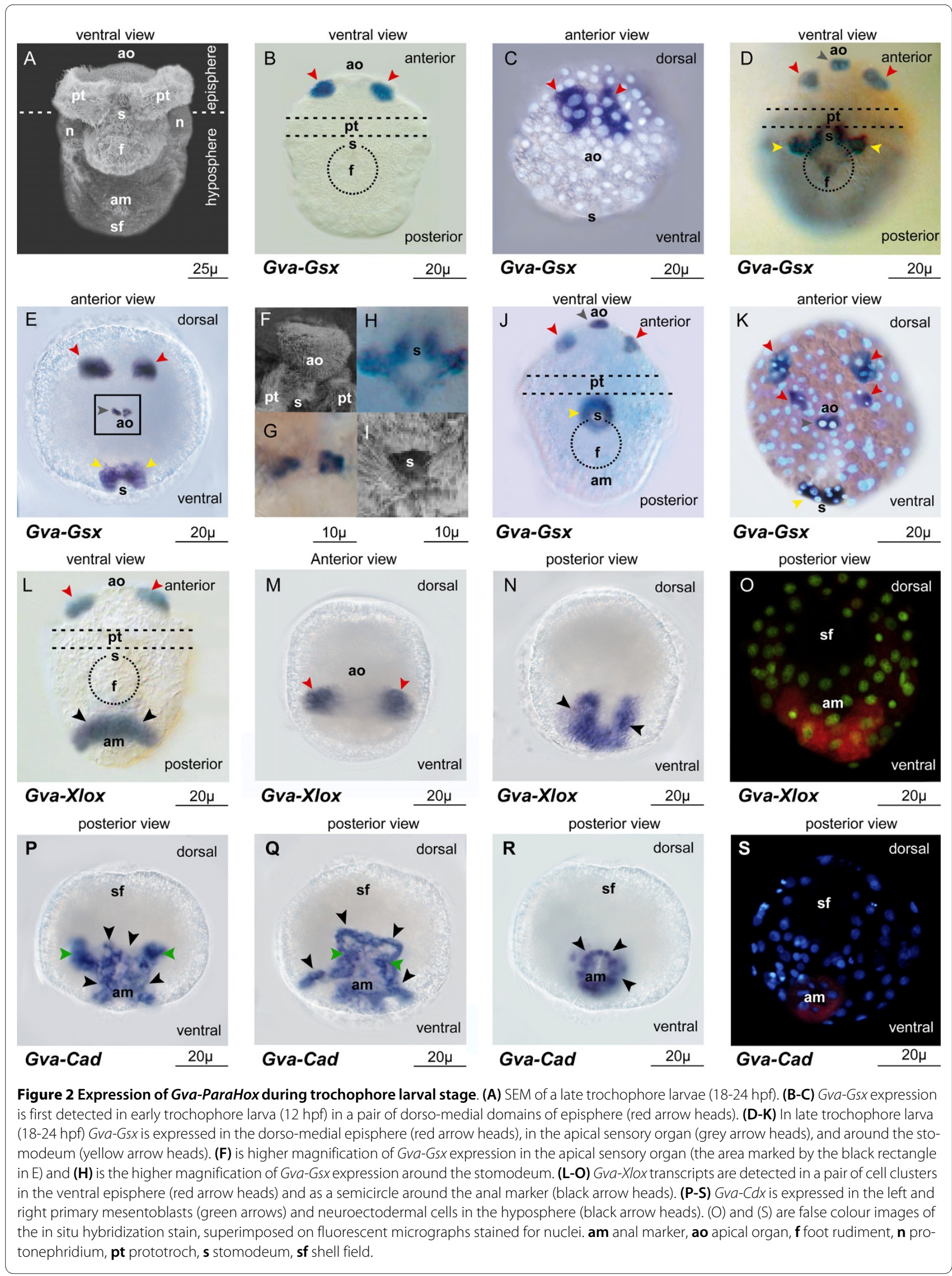


and 2Q). Using Patella vulgata as a reference, the latter expression of $P v u-C d x$ probably marks the left and right primary mesentoblasts (green arrows in Figure $2 \mathrm{P}$ and 2Q). Gva-Cdx-positive neuroectodermal cells are first observed as a patch of cells expressing this gene in varying intensities (Figure 2P). Gradually they migrate to the boundary of the expression area (Figure $2 \mathrm{Q}$ ) so that they from a circle of $G v a-C d x$-expressing cells around the anal marker at $24 \mathrm{hpf}$ (Figure $2 \mathrm{R}$ and $2 \mathrm{~S}$ ). The expression of $G v a-C d x$ around the anal marker at 24 hpf partly overlaps with the expression of Gva-Xlox in the ventral area at this stage, which is visible as a semicircle located ventrally around the anal marker (Figure $2 \mathrm{~N}$ and $2 \mathrm{R}$ ).

\section{ParaHox gene expression in the pretorsional veliger larva}

The transcripts of all three Gva-ParaHox genes are detected almost simultaneously in the visceral mass area of the pretorsional veliger larva prior to torsion (36-48 $\mathrm{hpf}$ ), on the left side of the larva where the digestive gland is forming (Figure 3). At this stage, the velum forms a complete circle and a pair of apical tufts is observed in the velar area (Figures 3A, B, and 3C). In addition to the apical tufts, there are "sensory cups" in the velar area. These are ciliated pockets embedded within the apical ganglion (Figure 3B). The expression of Gva-Gsx observed in the area of the mouth opening and of the apical organ of the late trochophore larva (Figure $2 \mathrm{~J}$ and $2 \mathrm{~K}$ ) is retained in the pretorsional veliger (Figure 3D). Gva-Gsx transcripts are also detected in the ventral part of the forming digestive gland in the left side of the visceral mass (Figure 3D and 3E). Gva-Gsx-positive signals are further detected in the area of the mouth opening (Figure 3E) and in five cells in the area of the apical organ (Figure 3D), the two apical tuft cells (Figure 3F), and the sensory cup cells (compare Figures 3B and 3D). Similar to Gva-Gsx, Gva-Xlox is expressed in the left side of the pretorsional veliger in the forming digestive gland (Figure 3G). The expression area of Gva-Xlox is located in the ventral part of the digestive gland, more dorsally but partly overlapping Gva-Gsx expression (Figure 3G and $3 \mathrm{H}$ ). The expression pattern of Gva-Xlox detected on the ventral side of the episphere of the late trochophore larva (Figure $2 \mathrm{~L}$ and $2 \mathrm{M}$ red arrow heads) is lost in the pretorsional veliger stage (Figure 3G and 3I). Additionally, five ectodermally derived Gva$X l o x$-positive cells appear on the right side of the larva prior to torsion (Figure 3I). Similar to the trochophore stage (Figure $2 \mathrm{M}$ and $2 \mathrm{O}$ ), these ectodermal cells form an incomplete circle and are presumably linked to the ventral nervous system (Figure 3J). Gva-Cad is expressed weakly in the whole area of the nascent digestive gland of the pretorsional veliger larva (Figure 3K). The intensity of expression is stronger in a few cells in the dorsal area of the visceral mass in the left side of the larva (Figure $3 \mathrm{~K}$ and $3 \mathrm{~L})$.

\section{Expression of ParaHox genes in veliger and competent larvae}

After torsion $(60 \mathrm{hpf})$, the velum reduces in size with a ventral split, and the mantle expands over the back of the head (Figure 4A). As the digestive tract continues to develop in the posttorsional veliger larva, expression patterns of Gva-ParaHox become more elaborated. At this stage, Gva-Gsx expression in the ventral part of the digestive gland and in the area of the mouth opening persists (Figure 4B and 4C). Sections reveal Gva-Gsx-positive cells at the ventral border of the area of yolk-filled cells (Figure 4D). Gva-Gsx transcripts are further apparent as paired domains beneath the apical organ where the formation of the cerebral ganglia commences (Figures 4C and 4D). At about three days post fertilization, expression of Gva-Gsx fades in the digestive gland. Instead, the gene is now expressed in the foregut around the area of the radula anlage (Figure $4 \mathrm{E}$ and $4 \mathrm{~F}$ ). At metamorphosis, when the apical sensory organ starts to dissociate, GvaGs $x$ continues to be expressed in the area of the cerebral ganglia (Figure 4F). Gva-Xlox expression persists on the left side of the visceral mass from the pretorsional to the posttorsional stages (Figure 4G and 4H). Sections through the left side of the larva reveal that these Gva$X l o x$-positive cells are part of the developing digestive gland (Figure 4J). Six or seven ectodermally-derived Gva$X l o x$-positive cells are located in the ventral part of the visceral mass (Figure 4G, H, and 4I). Gva-Cdx is mainly expressed in the newly formed hindgut and rectum, and weakly in the digestive gland (Figures $4 \mathrm{~K}$ and $4 \mathrm{~L}$ ).

\section{Post-larval ParaHox gene expression}

Serial section in situ hybridizations were used to trace the expression pattern of all three Gva-ParaHox in the hatchling (about four days after fertilization). No positive signals for Gva-Xlox and Gva-Cad transcripts are detected at this stage. Gva-Gsx is the only ParaHox gene that is expressed in the most posterior part of the radula sac during postlarval development (Figure 5). The juvenile hatchling has a complete radula with the radula sheath, buccal musculature, and radula bolsters (also called odontoblastic cartilages, Figure 5A). The posterior end of the radula sac forms the odontoblastic cushion which consists of a single-layered epithelium arranged in a semicircle and protruding into the sac's lumen. The epithelial cells are produced by two separated dorsolateral mitotic centres at the end of the sac (Figure 5B). Mitotic activity is scattered over the posterior area of odontoblastic cushions where the cells are small and undifferentiated. Towards the anterior of the cushions, the cells gradually elongate and form the tall odontoblastic epithelial cells (Figure 5B). Gva-Gsx transcripts are mainly detected in the paired odontoblastic cushions at the base of the radula (Figure $5 \mathrm{C}$; the weak signal observed in the pedal area seems to be unspecific). Gva-Gsx is expressed 


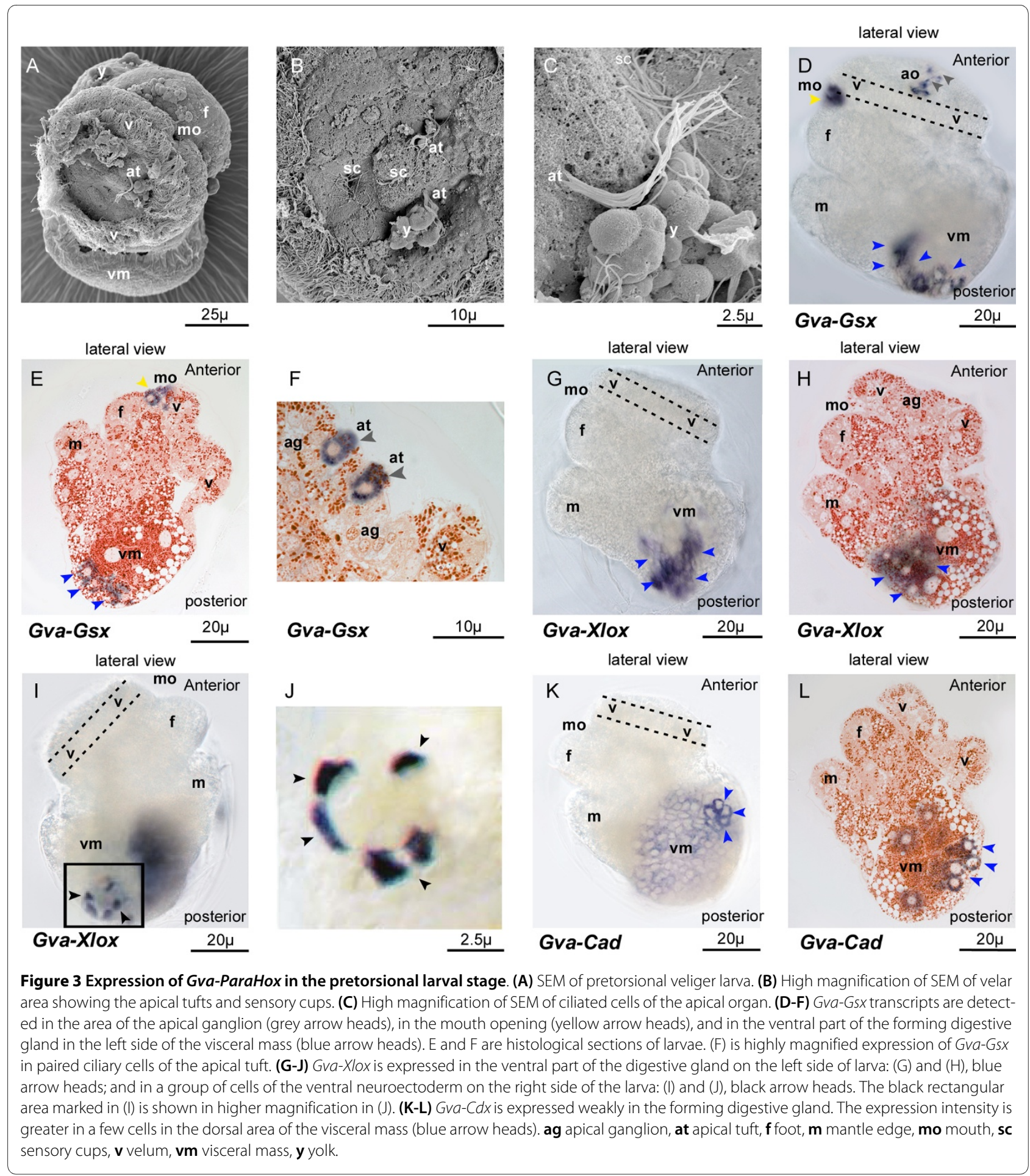

both in undifferentiated cells located at the back of the cushions and in odontoblastic epithelial cells. No transcripts were detected in the cells separating the two halves of the odontoblastic cushion (Figure 5D and 5E). The intensity of expression of Gva-Gsx diminishes gradually from posterior to anterior, i.e. from the undifferentiated cells to fully differentiated epithelial odontoblasts (Figure 5E).

\section{Discussion}

Is ParaHox gene expression colinear during patterning of gut?

It has been proposed that the origin of the three germ layered animals, the Bilateria, is associated with the innovation of several gene clusters of the ANTP family, with the $H o x$-cluster genes participating mainly in patterning of the neuroectoderm, the $\mathrm{NK}$-cluster genes in formation of 


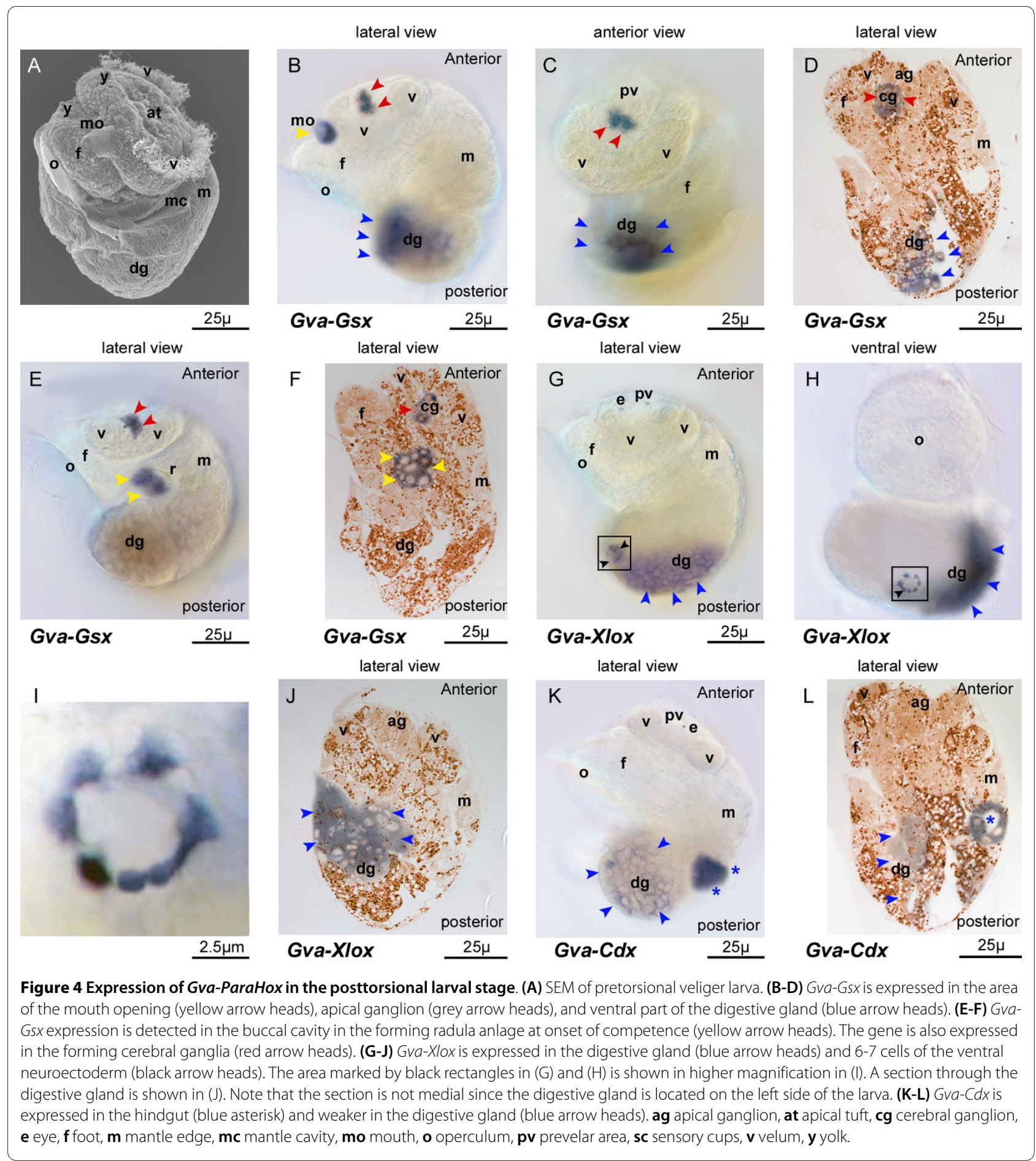

the mesodermal layers, and ParaHox in colinear regionalisation of the endoderm [1,3]. Of the animals studied to date, the chromosomal linkage of ParaHox genes has been shown only in amphioxus, mouse, and human $[1,3]$. The ParaHox genes are not linked in teleost fishes, the ascidian or the sea urchin $[27,28,59]$. The only description of the expression patterns of all three ParaHox genes for lophotrochozoans in relation to their genomic organi- sation is for the polychaete $P$. dumerilii [48]. Here, Gs $x$ and $X l o x$ are clustered and $C d x$ is separated, without clear evidence of colinear expression.

We were unable to detect clear colinear expression of ParaHox genes in Gibbula prior to torsion. If present, it is obscured by the permanent migration of cells from the digestive gland to their final positions in the gut, and by torsion processes. After torsion, however, a spatially 


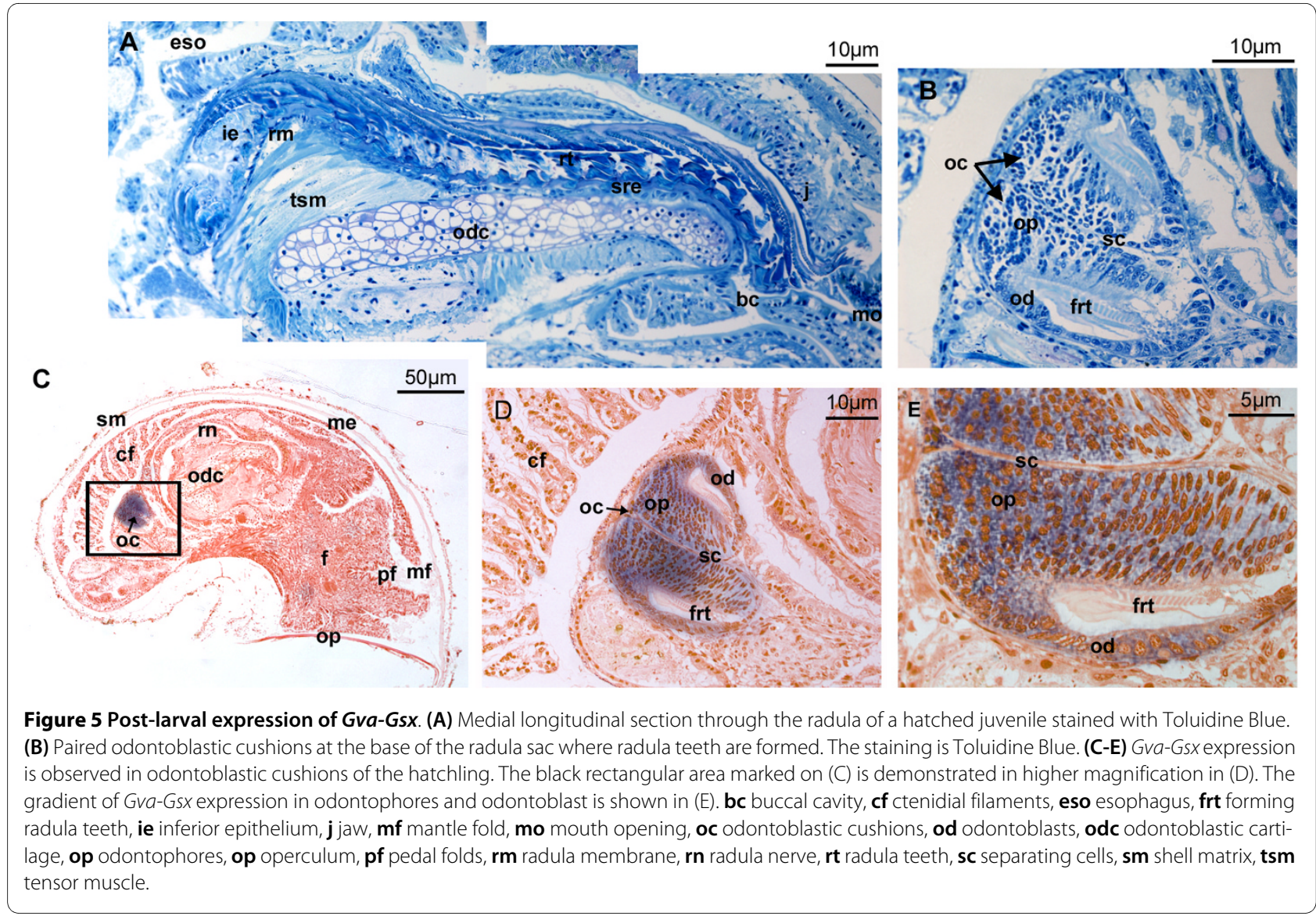

colinear expression of ParaHox genes is obvious in the digestive system, with Gva-Gsx patterning the mouth opening and radula anlage, Gva-Xlox expressed in the midgut, and Gva-Cdx in the hindgut (Figure 4 and 6). Therefore, our results support Holland's hypothesis that ParaHox genes are involved in gut regionalization along the anterior-posterior body axis in protostomes [3].

There also seems to be a temporal colinearity in expression of ParaHox genes in the gradual formation of the digestive system. In the trochophore larva, development of the digestive system begins with the formation of the stomodeum involving Gva-Gsx expression only (Figure 6). Gva-Xlox and Gva-Cdx are expressed at later stages in the more posterior parts of the gut. When the patterning of the gut is completed in the hatchling, expressions of Gva-Xlox and Gva-Cdx cease while Gva-Gsx continues to be involved in the patterning of the radula (Figure 6). During postlarval development, Gva-Gsx is expressed in the paired odontoblastic cushions of Gibbula (Figure 5). The gradient of Gva-Gsx expression from posterior to anterior in the odontoblastic cushions suggests that this gene is associated with mitotic features of these cells and their ability to divide and replace the odontoblasts, rather than direct involvement in secretion of radula teeth.

\section{Expression of ParaHox genes in cephalic neural and neurosensory cells}

Gastropod larvae are well provisioned with multicellular sensory structures, but only the apical sensory organ is typically present in both plankton-feeding and nonplankton-feeding veligers [60]. This suggests that information detected by the apical sensory organ is important during the entire larval stage, regardless of the length of larval life or capacity for feeding. Moreover, the apical sensory organ disappears at metamorphosis in species

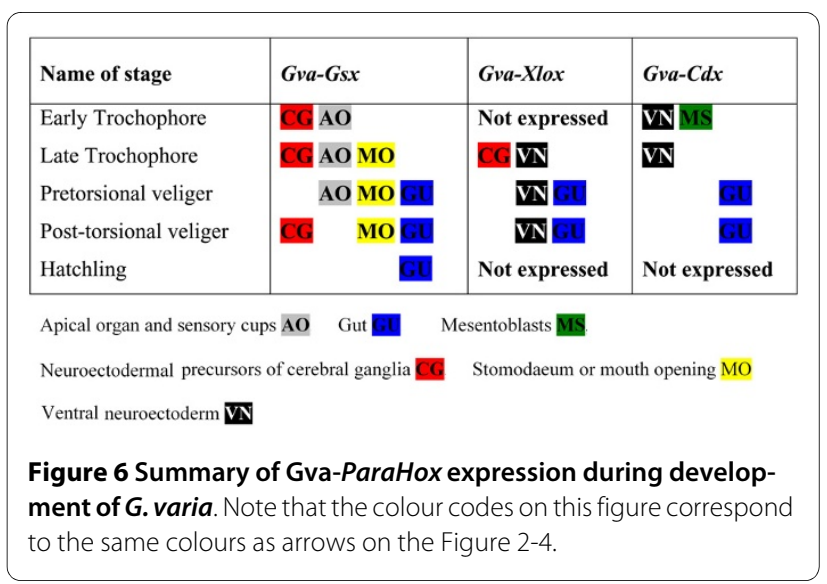


where this has been studied [61]. Therefore the apical sensory organ has functions restricted to the larval stage. During larval development in Gibbula, Gva-Gsx exhibits a complex pattern of expression in potential cephalic neural cells and in the apical organ. This pattern shows distinct similarity to $P d u-G s x$ expression in the trochophore stage in which $P d u$-Gsx expression is detectable in flask-shaped sensory-neurosecretory cells in the medial forebrain [48]. Prior to torsion, the Gva-Gsx pattern is spotted in the paired apical tufts and several neurosecretory cells or sensory cups of the apical organ (Figure 3 and 6). This gene also appears to be involved in the formation of parts of the cerebral ganglia from the apical sensory organ in competent larvae. This compares well to the polychaetes Capitella, Nereis, and Platynereis, where Gsx is expressed in the cerebral ganglia $[45,46,48]$. Our results may lend further support to the theory of complex ancestral expression of Gsx that was secondarily simplified in several lineages. In addition to Gva-Gsx expression in the dorsal episphere of the trochophore, Gva-Xlox is detected in a pair of expression domains located more ventrally. It is possible that these cells contribute to neural cells of future cerebral ganglia. However this pattern of expression is transient and is lost in later developmental stages.

\section{Possible expression of ParaHox genes in the trunk neuroectoderm}

Expression of ParaHox genes in ventral or dorsal neuroectoderm has been demonstrated in several species. Within Lophotrochozoa Capl-Cdx is expressed in posterior neuroectodermal cells in the polychaete Capitella. In Platynereis, $P d u-G s x$ is expressed in a central part of the larval ventral neuroectoderm in which somatic serotonergic neurons are identified [45,48]. Nereis is the only species studied so far in which all three ParaHox genes are known to be involved in patterning of the trunk neuroectoderm [46]. In Gibbula, Gva-Xlox and Gva-Cdx are expressed around the anal marker in the trochophore larvae. It has been shown that these cells express SoxB in the prospective neuroectoderm of the trunk in Patella [62]. Therefore, it is likely that these cells expressing Gva-Xlox and $G v a-C d x$ contribute to the trunk neuroectoderm. Temporary expression of Gva-Cdx in ventral neuroectoderm earlier during development, and expression of Gva$X l o x$ in overlapping regions at a later stage (Figure 6), may suggest that $G v a-C d x$ contributes to patterning of ventral neuroectoderm upstream of Gva-Xlox.

\section{Hypothetical ancestral ParaHox gene expression}

Comparative analyses across the animal kingdom show conservation of ParaHox gene expression domains in distinct tissues. Comparing Platynereis ParaHox gene expression to that of the orthologues in deuterostomes and ecdysozoans, Hui et al. 2009 confirmed Holland's hypothesis about the ancestral role of ParaHox genes, suggesting that the pattern of Gsx expression in the protostome-deuterostome ancestor was complex, with Gsx domains in several structures of the nervous system, and was secondarily reduced to small patches of expression in the anterior CNS in several lineages [48]. Holland's model further suggests that Gsx was expressed in the mouth region of the last bilaterian ancestor [3]. Lack of Gsx expression in the anterior gut of deuterostomes is explained by loss of the primary mouth and evolution of a new secondary mouth [3]. If this be the case, protostomes should maintain Gsx expression in anterior gut structures. Capitella results do not support such a model since CapI-Gsx expression is limited to a restricted region of the forming brain. The expression of Nvi-Gsh, Pdu-Gsx, and Gva-Gsx described here provides further support to the ancestral mouth patterning role of Gsx $[46,48]$.

$X l o x$ is expressed during midgut development in annelids [45,46,48-50]. Pdu-Xlox and Nvi-Xlox are also expressed in the nervous system. In Gibbula, Gva-Xlox pattern is detected in the digestive gland and ventral neuroectoderm, and expression in potential cephalic nerve cells is transient. Therefore, our results provide additional support that the expression of Xlox may reflect an ancestral function in central regions of the gut as well as a role in the nervous system. If this hypothesis is true, however, it would once more imply secondary simplification and loss of neural Xlox expression in several lineages [45]. However, the possibility that ancestral Xlox expression was simple and has become more complicated in different lineages cannot be ruled out since Xlox is expressed in ventral neuroectoderm in Nereis and Gibbula, in addition to cerebral ganglia, but is lacking in all other protostomes studied to date [46].

$C d x$ shows a complex, dynamic pattern of expression in cells of the ectoderm, endoderm and possibly mesoderm, extending to extremely anterior regions in all annelids studied so far [45-48,51]. This anterior expression of $C d x$ was also recently described in the acoel flatworm, Convolutriloba longifissura [63]. ClCdx is expressed in the commissures posterior to the statocyst, following the paths of nerve tracks and extending anteriorly. $C l C d x$ is also expressed in an area surrounding the eyes, forming direct connections to the brain commissure [63]. $C d x$ anterior expression seems to be the case in the limpet Patella as well, in which the gene is expressed in posterior ectoderm during gastrulation. The posterior ectodermal expression starts to fade in the trochophore, while expression extends anteriorly in the shape of an incomplete equatorial ring of ectodermal cells that corresponds to some cells of the prototroch [53]. Later in the young free swimming trochophore, $P v u-C d x$ expression in the prototroch disappears. The gene is also transiently expressed in the 
stomodeum [53]. Gva-Cdx expression differs from that of $P v u-C d x$ by being absent during gastrulation. In addition, we did not detect any sign of Gva-Cdx expression in the trochophore prototroch or stomodeum. In contrast, the detection of $C d x$ in mesentoblasts and in ectodermal cells situated on the posterior most part of the ventral side of the trochophore is a common feature in Gibbula and Patella. These are some of the cells that also express SoxB, a neurectodermal marker [62]. Therefore, $C d x$ seems to pattern the ventral neuroectoderm as well as mesentoblasts in gastropods. Anterior expression of $C d x$ was not observed during the larval development of Gibbula at any stage. This can be either interpreted as secondary loss of the anterior function of $C d x$ in Gibbula, or as a gain of function for this gene in several tissues in other species. The first possibility has been favoured since it can be explained by the separation of the gene from the cluster [48]. Nonetheless, variety in the pattern of expression of $C d x$ in different animals can serve as another example for the plasticity of gene expression during evolution. Whether the expression of the ParaHox genes in nervous systems is related to their function in the gut, i.e. innervation of different parts of the gut and/ or to feeding behaviour, awaits future research. Gene function experiments, therefore, would be desirable to give us better understanding of how these genes are employed.

\section{Conclusions}

The expression of ParaHox genes during anterior-posterior development of the digestive system (with Gsx patterning the mouth and foregut, Xlox patterning the midgut or digestive gland, and $C d x$ patterning the hindgut) suggests that these genes are involved in anterior-posterior specification of the G. varia gut. Our results support Holland's hypothesis that ParaHox genes are involved in gut regionalization and offer further support to the ancestral mouth patterning role of Gsx in protostomes. All three ParaHox genes of G. varia are involved in patterning of the nervous system. Gva-Gsx and Gva-Xlox are expressed in neural precursors of cerebral ganglia, the expression domain of these two genes does not coincide in the episphere and fades away in the case of Gva-Xlox in later larval stages. Additionally, GvaGsx patterns the neurosensory cells of the apical organ. Gva-Xlox and Gva-Cdx pattern the ventral neuroectoderm with $C d x$ possibly acting upstream of Xlox. During postlarval development, Gva-Gsx transcripts are detected in the precursor cells of odontoblasts at the base of the radula sac. This is probably a molluscan novelty related to radula evolution. Further research in other molluscan classes and use of experimental tools, e.g. RNAi, are required to improve our understanding of gene functions and enable a sound reconstruction of their ancestral role.

\section{Methods}

\section{Snail culturing}

The adults of Gibbula varia (L.) were collected in Crete, Greece and cultured in 150-200 liter aquariums in artificial sea water at $22^{\circ} \mathrm{C}$ (salinity $28^{\circ}$ ). Copulation was induced by lowering the salinity a few degrees by adding fresh water to the aquariums at $17^{\circ} \mathrm{C}$ (personal observation of Achim Meyer, The Johannes Gutenberg University of Mainz).

\section{Cloning of ParaHox genes}

DNA extraction was performed using the PeqGOLD Tissue DNA kit (PEQLAB Biotechnologie GmbH, Polling, Austria) according to the manufacturer's instructions. Homeobox fragments of ParaHox genes were obtained by polymerase chain reaction (PCR) from genomic DNA using Hox degenerate primers described previously $[64,65]$. These primers produce PCR amplification products that are mixtures of different fragments containing homeobox. The PCR fragments were purified using peqGOLD MicroSpin Cycle-Pure Kit (PEQLAB Biotechnologie $\mathrm{GmbH}$, Polling, Austria). Purified PCR products were cloned with the TOPO TA Cloning Kit (Invitrogen $\mathrm{GmbH}$, Karlsruhe, Germany). In total 255 clones were sequenced and all eleven Hox genes (Samadi and Steiner, unpublished data) and the three ParaHox genes were recovered. RNA was extracted from blastula and gastrula stages, trochophore, veliger, and competent larvae, and encapsulated juveniles using RNeasy Mini Kit (QIAGEN Vertriebs GmbH, Vienna, Austria). The cDNA from each developmental stage was synthesized using SuperScript ${ }^{\circ}$ III reverse transcriptase (Invitrogen $\mathrm{GmbH}$, Karlsruhe, Germany). The homeobox fragments were used to design primers for rapid amplification of cDNA ends (RACE). The RACE was performed with modifications according to Schramm et al. 2000 [66]. For further details on RACE protocol see supplementary data of [67]. The RACE products were cloned by the Topo-TA cloning kit (Invitrogen $\mathrm{GmbH}$, Karlsruhe, Germany) and sequenced using a BigDye Terminator v3.1 Cycle Sequencing Kit (Applied Biosystems, Foster City, CA, USA) and run on an ABI 3130xl DNA analyser automated capillary sequencer.

\section{Orthology assignment and phylogenetic analyses}

The initial orthology of the ParaHox genes was tested by searching against GenBank non-redundant protein databases using the BlastX algorithm. The genes were named Gva-Gsx, Gva-Xlox, and Gva-Cdx and deposited in GenBank under accession numbers HM136802, HM136803, HM136804, respectively. Orthology assignment of the genes was made based on phylogenetic analysis. The phy- 
logenetic analyses were carried out using amino acid sequences. We compiled a ParaHox gene alignment including representatives of bilaterians. Sequences were aligned using the program ClustalX v.2.0.10. First the homeobox region was aligned, then, using the homeobox as an anchor, the flanking regions were aligned and subsequent trimming carried out manually. Bayesian inference on amino acid data using MrBayes version 3.1.1 was applied for orthology analysis, with $2 \times 4$ Markov chains under the Jones amino acid substitution model [68]. Chains were run for five million generations with a sampling frequency of 1000 generations and the burnin set to 5000 generations.

\section{Whole-mount in situ hybridization}

The Maxiscript T7 and SP6 RNA polymerase kit (Ambion, Austin, USA) was used to synthesize the sense and anti-sense probes that were labelled by the Dig RNA labelling kit (Roche Molecular Biochemicals, Vienna, Austria). WMISH was performed with few modifications after Lespinet et al. 2002 [69]. DIG-labelled riboprobes were detected colourimetrically with NBT/BCIP substrates. The details of modifications can be found in [67]. For WMISH, embryos were mounted in $70 \%$ glycerol and the expression patterns were documented. For serial-sectioned in situ hybridization, embryos were embedded in Epoxy resin after in situ hybridization according to the standard protocols, and sectioned with a microtome at a thickness of $2 \mu \mathrm{m}$. Sections were stained with Eosin using standard histological protocols.

\section{Scanning-electron microscopy}

Larvae were fixed in $4 \%$ paraformaldehyde (PFA) in $0.1 \mathrm{M}$ saline phosphate buffer (PBS) for $4 \mathrm{~h}$ at room temperature or overnight at $4{ }^{\circ} \mathrm{C}$, washed three times for $15 \mathrm{~min}$ in PBS containing $0.1 \%$ sodium azide (NaN3), postfixed in osmium tetroxide ( $1 \%$ in distilled water for $2 \mathrm{~h}$ at room temperature), followed by three washes in distilled water, and dehydrated in a graded ethanol/acetone series. Drying was performed either by critical point dryer or chemical drying with HMDS (Hexamethyldisilazane). After drying, the samples were mounted on scanning electron microscopy (SEM) stubs, sputter-coated with gold, and observed with a LEO 1430VP scanning electron microscope.

\section{Additional material}

Additional file 1 General aspect of development and differentiation of gut in G. varia.

Additional file $\mathbf{2}$ Species names and Gene Bank accession numbers of the genes used in phylogenetic analyses and alignments of each $G$. varia ParaHox amino acid sequence to their representatives from other animals.

\section{Abbreviations}

BCIP: 5-bromo-4-chloro-3-indolyl-phosphate; CNS: central nervous system; hpf: hours post fertilization; HMDS: Hexamethyldisilazane; NBT: nitro blue tetrazolium chloride; ORF: open reading frame; RACE: rapid amplification of CDNA ends; RNAi: RNA interference; SEM: scanning electron micrograph; WMISH: whole-mount in situ hybridization.

\section{Authors' contributions}

LS established the animal cultures, sequenced the ParaHox genes, performed WMISH experiments, and wrote the first draft of the manuscript. GS is responsible for the supervision of the project, the phylogenetic analyses, and editing of the manuscript. Both authors have read and approved the final manuscript.

\section{Acknowledgements}

The authors are grateful to two anonymous reviewers for their helpful comments. LS was supported by an EC fellowship within the MOLMORPH network under the $6^{\text {th }}$ Framework Programme "Marie Curie Fellowships for Early Stage Research Training (EST) (Contract number MEST-CT-2005 - 020542). We are greatly indebted to Mariti Steiner for the considerable improvement of the English.

\section{Author Details}

Molecular Phylogenetics, Department of Evolutionary Biology, Faculty of Life Sciences, University of Vienna, Vienna, Austria

Received: 17 February 2010 Accepted: 12 July 2010

Published: 12 July 2010

\section{References}

1. Brooke NM, Garcia-Fernàndez J, Holland PWH: The ParaHox gene cluster is an evolutionary sister of the Hox gene cluster. Nature 1998, 392:920-922.

2. Finnerty JR, Martindale MQ: Ancient origins of axial patterning genes: Hox genes and ParaHox genes in the Cnidaria. Evol Dev 1999, 1:16-23.

3. Holland PW: Beyond the Hox : how widespread is homeobox gene clustering? Journal of Anatomy 2001, 199:13-24.

4. Hill A, Wagner A, Hill M: Hox and paraHox genes from the anthozoan Parazoanthus parasiticus. Molecular Phylogenetics and Evolution 2003, 28:529-535.

5. Garcia-Fernàndez J: Hox, ParaHox, Proto Hox: facts and guesses. Heredity 2005, 94:145-152.

6. Maclean JA, Chen MA, Wayne CM, Bruce SR, Rao M, Meistrich ML, Macleod C, Wilkinson MF: Rhox: a new homeobox gene cluster. Cell 2005, 120:369-382.

7. Chourrout D, Delsuc F, Chourrout P, Edvardsen RB, Rentzsch F, Renfer E, Jensen MF, Zhu B, de Jong P, Steele RE, Technau U: Minimal Proto Hox cluster inferred from bilaterian and cnidarian Hox complements. Nature 2006, 442:684-687.

8. Hsieh-Li HM, Witte DP, Szucsik JC, Weinstein M, Li H, Potter SS: Gsh-2, a murine homeobox gene expressed in the developing brain. Mech Dev 1995, 50:177-186.

9. Valerius MT, Li H, Stock JL, Weinstein M, Kaur S, Singh G, Potter SS: Gsh-1 : a novel murine homeobox gene expressed in the central nervous system. Dev Dyn 1995, 203:337-351.

10. Li H, Zeitler PS, Valerius MT, Small K, Potter SS: Gsh-1, an orphan Hox gene, is required for normal pituitary development. EMBO J 1996, 15:714-724.

11. Szucsik JC, Witte DP, Li H, Pixley SK, Small KM, Potter SS: Altered forebrain and hindbrain development in mice mutant for the Gsh-2 homeobox gene. Dev Biol 1997, 191:230-242.

12. Deschet K, Bourrat F, Chourrout D, Joly JS: Expression domains of the medaka (Oryzias latipes) Ol-Gsh 1 gene are reminiscent of those of clustered and orphan homeobox genes. DevGenes Evol 1998, 208:235-244.

13. Cheesman SE, Eisen JS: Gsh1 demarcates hypothalamus and intermediate spinal cord in zebrafish. Gene Expr Patterns 2004 5:107-112.

14. Wright CVE, Schnegelsberg P, De Robertis EM: XIHbox 8: a novel Xenopus homeo protein restricted to a narrow band of endoderm. Development 1989, 105:787-794.

15. Levine $E M$, Schechter $\mathrm{N}$ : Homeobox genes are expressed in the retina and brain of adult goldfish. Proc Natl Acad Sci USA 1993, 90:2729-2733. 
16. Jonsson J, Carlsson L, Edlund T, Edlund H: Insulin-promoter-factor 1 is required for pancreas development in mice. Nature 1994, 371:606-609.

17. Offield MF, Jetton TL, Labosky PA, Ray M, Stein RW, Magnuson MA, Hogan $\mathrm{BL}$, Wright CV: $P D X-1$ is required for pancreatic outgrowth and differentiation of the rostral duodenum. Development 1996, 122:983-995

18. Milewski WM, Duguay SJ, Chan SJ, Steiner DF: Conservation of PDX-1 structure, function, and expression in zebrafish. Endocrinology 1998, 139:1440-1449.

19. Perez-Villamil B, Schwartz PT, Vallejo M: The pancreatic homeodomain transcription factor IDX1/IPF1 is expressed in neural cells during brain development. Endocrinology 1999, 140:3857-3860

20. Assouline B, Nguyen V, Mahe S, Bourrat F, Scharfmann R: Development of the pancreas in medaka. Mech Dev 2002, 117:299-303.

21. Frumkin A, Rangini Z, Ben-Yehuda A, Gruenbaum Y, Fainsod A: A chicken caudal homologue, $\mathrm{CHox}$-cad, is expressed in the epiblast with posterior localization and in the early endodermal lineage. Development 1991, 112:207-219.

22. Gamer LW, Wright CV: Murine $C d x-4$ bears striking similarities to the Drosophila caudal gene in its homeodomain sequence and early expression pattern. Mech Dev 1993, 43:71-81.

23. Joly JS, Maury M, Joly C, Duprey P, Boulekbache H, Condamine H: Expression of a zebrafish caudal homeobox gene correlates with the establishment of posterior cell lineages at gastrulation. Differentiation 1992, 50:75-87.

24. Reece-Hoyes JS, Keenan ID, Isaacs HV: Cloning and expression of the $C d x$ family from the frog Xenopus tropicalis. Dev Dyn 2002, 223:134-140.

25. Hudson C, Lemaire $P$ : Induction of anterior neural fates in the ascidian Ciona intestinalis. Mech Dev 2001, 100:189-203.

26. Corrado M, Aniello F, Fucci L, Branno M: Ci-IPF1, the pancreatic homeodomain transcription factor, is expressed in neural cells of Ciona intestinalis larva. Mech Dev 2001, 102:271-274.

27. Ferrier DEK, Holland PWH: Ciona intestinalis ParaHox genes: evolution of Hox/ParaHox cluster integrity, developmental mode, and temporal colinearity. Mol Phylogenet Evol 2002, 24:412-417.

28. Arnone Ml, Rizzo F, Annunciata R, Cameron RA, Peterson KJ, Martinez P: Genetic organization and embryonic expression of the ParaHox genes in the sea urchin S. purpuratus: insights into the relationship between clustering and colinearity. Dev Biol 2006, 300:63-73.

29. Hwang SP, Wu JY, Chen CA, Hui CF, Chen CP: Novel pattern of AtXlox gene expression in starfish Archaster typicus embryos. Dev Growth Differ 2003, 45:85-93.

30. Weiss JB, Von Ohlen T, Mellerick DM, Dressler G, Doe CQ, Scott MP: Dorsoventral patterning in the Drosophila central nervous system: the intermediate neuroblasts defective homeobox gene specifies intermediate column identity. Genes Dev 1998, 12:3591-3602.

31. Wheeler SR, Carrico ML, Wilson BA, Skeath JB: The Tribolium columnar genes reveal conservation and plasticity in neural precursor patterning along the embryonic dorsal-ventral axis. Dev Biol 2005, 279:491-500.

32. Mlodzik M, Fjose A, Gehring WJ: Isolation of caudal, a Drosophila homeobox-containing gene with maternal expression, whose transcripts form a concentration gradient at the preblastoderm stage. EMBO J 1985, 4:2961-2969.

33. Schulz C, Schroder R, Hausdorf B, Wolff C, Tautz D: A caudal homologue in the short germ band beetle Tribolium shows similarities to both, the Drosophila and the vertebrate caudal expression patterns. Dev Genes Evol 1998, 208:283-289.

34. Olesnicky EC, Brent AE, Tonnes L, Walker M, Pultz MA, Leaf D, Desplan C: A caudal mRNA gradient controls posterior development in the wasp Nasonia. Development 2006, 133:3973-3982

35. Xu X, Xu PX, Suzuki Y: A maternal homeobox gene, Bombyx caudal, forms both mRNA and protein concentration gradients spanning anteroposterior axis during gastrulation. Development 1994, $120: 277-285$.

36. Shinmyo Y, Mito T, Matsushita T, Sarashina I, Miyawaki K, Ohuchi H, Noji S: caudal is required for gnathal and thoracic patterning and for posterior elongation in the intermediate-germband cricket Gryllus bimaculatus. Mech Dev 2005, 122:231-239.

37. Dearden PK, Akam M: Early embryo patterning in the grasshopper, Schistocerca gregaria: wingless, decapentaplegic and caudal expression. Development 2001, 128:3435-3444.
38. Copf T, Rabet N, Celniker SE, Averof M: Posterior patterning genes and the identification of a unique body region in the brine shrimp Artemia franciscana. Development 2003, 130:5915-5927.

39. Rabet N, Gibert JM, Queinnec E, Deutsch JS, Mouchel-Vielh E: The caudal gene of the barnacle Sacculina carcini is not expressed in its vestigial abdomen. Dev Genes Evol 2001, 211:172-178.

40. Abzhanov A, Kaufman TC: Embryonic expression patterns of the Hox genes of the crayfish Procambarus clarkii (Crustacea, Decapoda). Evol Dev 2000, 2:271-283.

41. Akiyama-Oda Y, Oda H: Early patterning of the spider embryo: a cluster of mesenchymal cells at the cumulus produces Dpp signals received by germ disc epithelial cells. Development 2003, 130:1735-1747.

42. Chipman AD, Arthur W, Akam M: A double segment periodicity underlies segment generation in centipede development. Curr Biol 2004, 14:1250-1255.

43. Waring DA, Kenyon C: Regulation of cellular responsiveness to inductive signals in the developing C. elegans nervous system. Nature 1991, 350:712-715.

44. Ruvkun G, Hobert O: The taxonomy of developmental control in Caenorhabditis elegans. Science 1998, 282:2033-2041.

45. Fröbius AC, Seaver EC: ParaHox gene expression in the polychaete annelid Capitella sp. I. Dev Genes Evol 2006, 216:81-88.

46. Kulakova MA, Cook CE, Andreeva TF: ParaHox gene expression in larval and postlarval development of the polychaete Nereis virens (Annelida, Lophotrochozoa). BMC Dev Biol 2008, 8:61.

47. de Rosa R, Prud'homme B, Balavoine G: Caudal and even-skipped in the annelid Platynereis dumerilii and the ancestry of posterior growth. Evol Dev 2005, 7:574-587.

48. Hui JHL, Raible F, Korchagina N, Dray N, Samain S, Magdelenat G, Jubin C, Segurens B, Balavoine G, Arendt D, Ferrier DEK: Features of the ancestral bilaterian inferred from Platynereis dumerilii ParaHox genes. BMC Biology 2009, 7:43

49. Wedeen CJ, Shankland M: Mesoderm is required for the formation of a segmented endodermal cell layer in the leech Helobdella. Dev Biol 1997, 191:202-214.

50. Wysocka-Diller J, Aisemberg GO, Macagno ER: A novel homeobox cluster expressed in repeated structures of the midgut. Dev Biol 1995, 171:439-447.

51. Matsuo K, Yoshida H, Shimizu T: Differential expression of caudal and dorsal genes in the teloblast lineages of the oligochaete annelid Tubifex tubifex. Dev Genes Evol 2005, 215:238-247.

52. Ferrier DEK, Holland PWH: Sipunculan ParaHox genes. Evol Dev 2001, 3:263-270.

53. Le Gouar M, Lartillot N, Adoutte A, Vervoort M: The expression of a caudal homologue in a mollusc, Patella vulgata. Gene Expr Patterns 2003, 3:35-37.

54. Barucca M, Biscotti MA, Olmo E, Canapa A: All the three ParaHox genes are present in Nuttallochiton mirandus (Mollusca: polyplacophora): evolutionary considerations. J Exp Zoolog B Mol Dev Evol 2006, 306:164-167.

55. Canapa A, Biscotti MA, Olmo E, Barucca M: Isolation of Hox and ParaHox genes in the bivalve Pecten maximus. Gene 2005, 348:83-88.

56. Ponder WF, Lindberg DR: Gastropoda phylogeny - challenges for the 90s. In Origin and Evolutionary Radiation of the Mollusca Edited by: Taylor J. Oxford University Press, Oxford; 1996:135-154.

57. Underwood AJ: Spawning, larval development and settlement behaviour of Gibbula cineraria (Gastropoda: Prosobranchia) with a reappraisal of torsion in gastropods. Marine Biology 1972, 17:341-349.

58. Crofts DR: The development of Haliotis tuberculata, with special reference to organogenesis during torsion. Phil Trans Royal Soc London 1937, 22813:219-268.

59. Mulley JF, Chiu CH, Holland PWH: Breakup of a homeobox cluster after genome duplication in teleosts. Proc Natl Acad Sci USA 2006, 103:10369-10372

60. Page LR: Comparative structure of the larval apical sensory organ in gastropods and hypotheses about function and developmental evolution. Invertebr Reprod Dev 2002, 41:193-200.

61. Gifondorwa DJ, Leise EM: Programmed cell death in the apical ganglion during larval metamorphosis of the marine mollusc llyanassa obsoleta. Biol Bull 2006, 210:109-120. 
62. Le Gouar M, Guillou A, Vervoort A: Expression of a SoxB and a Wnt2/13 gene during the development of the mollusc Patella vulgata. Dev Genes Evol 2004, 214:250-256.

63. Hejnol A, Martindale MQ: Coordinated spatial and temporal expression of Hox genes during embryogenesis in the acoel Convolutriloba longifissura. BMC Biology 2009, 7:65.

64. Murtha MT, Leckman JF, Ruddle FH: Detection of homeobox genes in development and evolution. Proc Natl Acad Sci USA 1991, 88:10711-10715.

65. Passamaneck YJ, Halanych KM: Evidence from Hox genes that bryozoans are lophotrochozoans. Evol Dev 2004, 4:275-281.

66. Schramm G, Bruchhaus I, Roeder T: A simple and reliable 5'-RACE approach. Nucleic Acids Research 2000, 28:96-99.

67. Samadi L, Steiner G: Involvement of Hox genes in shell morphogenesis in the encapsulated development of a top shell gastropod (Gibbula varia L.). Dev Genes Evol 2009, 219:523-530.

68. Huelsenbeck JP, Ronquist F: MRBAYES: Bayesian inference of phylogenetic trees. Bioinformatics 2001, 17:754-755.

69. Lespinet O, Nederbragt AJ, Cassan M, Dictus WJAG, van Loon AE, Adoutte A: Characterization of two snail genes in the gastropod mollusc Patella vulgata : implications for understanding the ancestral function of the snail-related genes in Bilateria. Dev Genes Evol 2002, 212:186-195.

\section{doi: 10.1186/1471-213X-10-74}

Cite this article as: Samadi and Steiner, Conservation of ParaHox genes'

function in patterning of the digestive tract of the marine gastropod Gibbula varia BMC Developmental Biology 2010, 10:74

\section{Submit your next manuscript to BioMed Central} and take full advantage of:

- Convenient online submission

- Thorough peer review

- No space constraints or color figure charges

- Immediate publication on acceptance

- Inclusion in PubMed, CAS, Scopus and Google Scholar

- Research which is freely available for redistribution

Submit your manuscript at www.biomedcentral.com/submit
C) Biomed Central 